\title{
Species selection for pharmacognostic studies
}

\author{
lan Edwin Cock
}

Biomolecular and Physical Sciences, Environmental Futures Centre, Nathan Campus, Griffith University, 170 Kessels Rd, Nathan, Brisbane, Queensland 4111, Australia

Submitted: 16-05-2012

Published: 02-08-12

Despite the enormous potential of plants and the long history of medicinal plant usage, the field of pharmacognosy remains relatively under studied. It has been estimated that $<10 \%$ of the approximately 300,000 500,000 species of plants worldwide have been studied for one or more bioactivities. ${ }^{[1]}$ Yet plant derived medicines account for a major proportion of modern drugs, with estimates that more than $25 \%$ of prescription drugs contain at least one ingredient derived from plants. Furthermore, natural medicines remain widely used, in developed as well as in developing countries. With so many plants yet to be tested and the huge potential of pharmacognosy/ phytopharmacology, it is essential for researchers to narrow the field. Several criteria are useful in selecting plants for study.

\section{ETHNOBOTANY/ETHNOPHARMACOLOGY}

Given the wide choice of plants yet to be studied, often a good starting point is to begin with plants with a documented history of usage by traditional healers. Traditional knowledge can serve as a powerful search engine, allowing the researcher to focus their attention on plants which were used to target medical conditions that the researcher wishes to study. All regions of the world had civilizations which used plant medicines although the degree of documentation of these systems varies. Indian Ayurvedic medicine and tradition Chinese medicine (TCM) are particularly well documented. It is therefore

\begin{tabular}{|l|l|}
\hline \multicolumn{2}{|c|}{ Access this article online } \\
\hline Quick Response Code: & \multirow{2}{*}{ Website: } \\
\cline { 1 - 2 } & www.phcog.com \\
\cline { 2 - 3 } & DOI: \\
\hline
\end{tabular}

Address for correspondence:

I. E. Cock, Biomolecular and Physical Sciences, Environmental

Futures Centre, Nathan Campus, Griffith University, 170 Kessels

Rd, Nathan, Brisbane, Queensland 4111, Australia.

E-mail: I.Cock@griffith.edu.au not surprising that a high proportion of published pharmacognostic studies focus on plants whose usage has been described in these medicinal systems. In contrast, documentation of medicinal plant usage in other parts of the world may be less complete and therefore of less use in species selection. In Australia for example, there is a long tradition of medicinal plant usage by indigenous Australians. This traditional knowledge was often passed on verbally, rather than by documentation resulting in much of this knowledge being irretrievably lost as the indigenous populations assimilates into the mainstream population and become increasingly reliant on allopathic medicines. This does not mean that ethnobotanical knowledge of Australian plants is not still available or useful. It may often still provide a starting point for pharmacognostic testing. However, it does mean that this knowledge is often more difficult to access and other methods of plant species selection may be required.

\section{FIELD OBSERVATIONS}

A researcher's own field observations are often valuable in selecting a plant species for testing. Plants which grow despite environmental stresses (e.g. plants growing in tropical rainforests where there is an abundance of insects, fungi and bacteria) may have adapted to produce phytochemicals which help protect the plant. These chemicals may also ultimately provide us with new medicines. Studies in my laboratory using species selection based on field observations have yielded interesting results. ${ }^{[2]}$ Xanthorrhoea johnsonii is an extremely long lived species with some plants being estimated at more than 550 years of age. They are also extremely slow growing with the growth rates estimated as low as $0.88 \mathrm{~cm} /$ year. Due to its slow growth rate, it was thought likely that $X$. johnsonii may have developed chemical protective mechanisms to deter foraging animals which could potentially threaten their survival. The number of animals that use $X$. jobnsonii as a food source is low and the leaves are generally not ingested. In studies in my laboratory, $X$. johnsonii leaves were found to have an apparent anesthetic effect similar to the effects previously described for tubocurarine, 
dimethyltubocurarine, and alcuronium (collectively known as curare, a South American arrow poison from Chondrodendron tomentosum) ${ }^{[2]}$

\section{TAXONOMIC CONSIDERATIONS}

Many plants which are not themselves known to have therapeutic value may be related to other species that are known to produce medicinally important phytochemicals. Many plant secondary metabolites are regarded as family or genus specific. Thus, investigation of species closely related to those know to have medicinal properties may detect similar bioactivities in these species. For example, the antibacterial properties of many Asian Syzygium species are well established. ${ }^{[3-5]}$ Recently, we have studied Australian Syzygium species and have demonstrated similar antibacterial activity for several species. ${ }^{[6,7]}$ Likewise, we recently demonstrated antibacterial properties for several Eucalypts closely related to species with known antiseptic properties. ${ }^{[8]}$

However, such an approach does not always yield similar bioactivities in closely related species. In a recent study, we screened a number of Aloe species for antimicrobial activity based on the well documented antiseptic properties of Aloe barbadensis, Aloe ferox, Aloe arborescens, and Aloe perryi baker. ${ }^{\left[{ }^{[]}\right]}$It was found that of the six other Aloe species tested, none showed any antiseptic properties at all. Despite examples such as this, species selection based on taxonomic similarity often yields interesting results.

\section{RANDOM SELECTION}

Random selection should not be overlooked when selecting plant species for medicinal tests. Given the vast number of plants that are yet to be thoroughly investigated, random testing may well result in exciting new discoveries. Many emerging diseases and medical conditions that early pharmacognosists were not exposed to or did not know about are now a common part of our life. Alzeheimer's disease, Parkinson's disease, multiple sclerosis, HIV, and many cancers were not major health concerns for our ancestors. Yet many of these diseases may nowadays affect us and/or our family and friends. Often, allopathic medicine is insufficient in the treatment of these conditions. Random testing may provide new insights and ultimately, better treatments for these diseases and conditions.

Pharmacognostic studies hold great potential in identifying and verifying therapeutic formulations. Furthermore, natural plant medicines have already provided us and will continue to provide a source of new pharmaceutical agents for further drug development. A well thought out approach to species selection for screening of medicinal properties will aid in this process and ensure a source of new natural medicines and lead products for further development into the future.

\section{REFERENCES}

1. Gilani $\mathrm{AH}$, Rahman $\mathrm{AU}$. Trends in ethnopharmocology. J Ethnopharmacol 2005;100:43-9.

2. Cock IE, Kalt FR. Toxicity evaluation of Xanthorrhoea johnsonii leaf methanolic extract using the Artemia franciscana bioassay. Pharmacogn Mag 2010;6:166-71.

3. Arora DS, Kaur GJ. Antibacterial activity of some Indian medicinal plants. J Nat Med 2007;61:313-7.

4. Mohanty S, Cock IE. Bioactivity of Syzygium jambos methanolic extracts: Antibacterial activity and toxicity. Pharmacognosy Res 2009;2:4-9.

5. Duraipandiyan V, Ayyanar M, Ignacimuthu S. Antimicrobial activity of some ethnomedicinal plants used by Paliyar tribe from Tamil Nadu, India. BMC Complement Altern Med 2006;6:35.

6. Cock IE. Antibacterial activity of selected Australian native plant extracts. Internet J Microbiol 2008;4,2.

7. Cock IE. Antibacterial activity of Syzygium australae and Syzygium leuhmanii leaf methanolic extracts. Pharmacognosy Comm 2012;2:71-7.

8. Cock IE. Antibacterial and antifungal activity of Eucalyptus major and Eucalyptus baileyana methanolic extracts. Internet $\mathrm{J}$ Microbiol 2009;6,1.

9. Mpala L, Chikowe G, Cock IE. No evidence of antiseptic properties and low toxicity of selected Aloe species. J Pharm Negat Results 2010;1:10-6.

Announcement

\section{iPhone App}

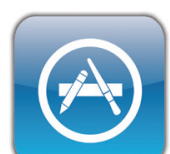

Download

iPhone, iPad application
A free application to browse and search the journal's content is now available for iPhone/iPad. The application provides "Table of Contents" of the latest issues, which are stored on the device for future offline browsing. Internet connection is required to access the back issues and search facility. The application is Compatible with iPhone, iPod touch, and iPad and Requires iOS 3.1 or later. The application can be downloaded from http://itunes.apple.com/us/app/medknow-journals/ $\mathrm{id} 458064375$ ? $\mathrm{s}=1 \& \mathrm{mt}=8$. For suggestions and comments do write back to us. 